Document downloaded from:

http://hdl.handle.net/10251/148915

This paper must be cited as:

Benajes, J.; García Martínez, A.; Monsalve-Serrano, J.; Boronat-Colomer, V. (2017). Gaseous emissions and particle size distribution of dual-mode dual-fuel diesel-gasoline concept from low to full load. Applied Thermal Engineering. 120:138-149. https://doi.org/10.1016/j.applthermaleng.2017.04.005

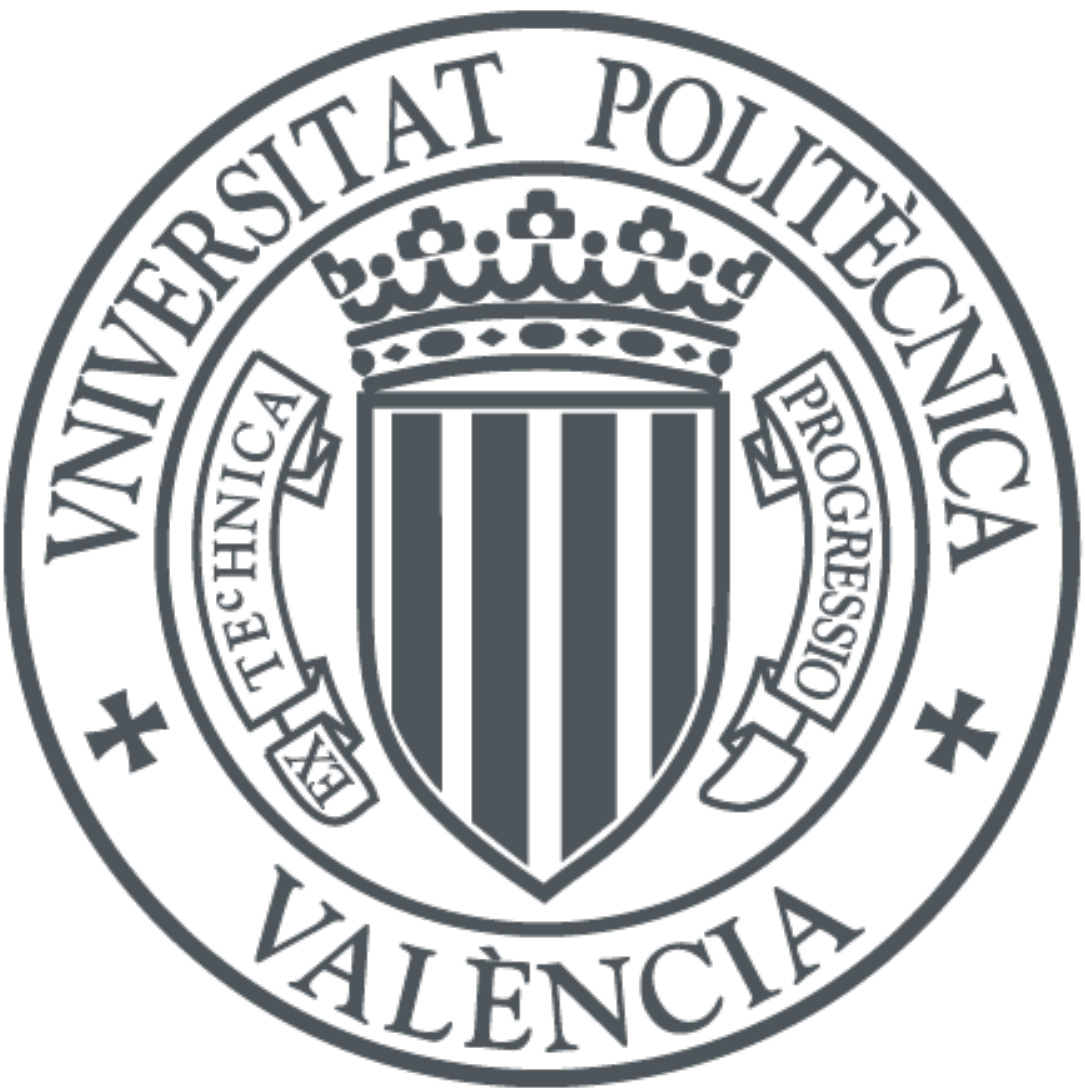

The final publication is available at

https://doi.org/10.1016/j.applthermaleng.2017.04.005

Copyright Elsevier

Additional Information 


\title{
Gaseous emissions and particle size distribution of dual-mode dual-fuel diesel- gasoline concept from low to full load
}

Applied Thermal Engineering, Volume 120, 25 Jun 2017, Pages 138-149.

http://dx.doi.org/10.1016/j.applthermaleng.2017.04.005

\author{
Jesús Benajes, Antonio García*, Javier Monsalve-Serrano and Vicente Boronat \\ CMT - Motores Térmicos, Universitat Politècnica de València, Camino de Vera s/n, \\ 46022 Valencia, Spain
}

Corresponding author $(*)$ :

Dr. Antonio García (angarma8@mot.upv.es)

Phone: +34 963879659

Fax: +34963877659

\begin{abstract}
Low temperature combustion concepts are in focus of study nowadays as a method to avoid the NOx-soot trade-off existing with conventional diesel combustion. One of the most promising strategy is known as reactivity controlled compression ignition because of its high thermal efficiency and the ultra-low nitrogen oxides and soot emissions. However, this concept presents several challenges such as the high levels of carbon monoxide and unburned hydrocarbons promoted at low load and unacceptable levels of pressure rise rate at high load. Therefore, to mitigate these shortcomings the dualmode dual-fuel concept, combining reactivity controlled compression ignition and diffusive dual-fuel diesel-gasoline combustion, has been developed.

Total number of particles is also limited by the emission standards. Previous studies focused in particles emissions carried out by the research community present particle size distribution, composition and mass of the particles on reactivity controlled compression ignition combustion mode. Additional studies were carried out in order to identify the components of these particles, being partially formed of volatiles, and reflects that particles are smaller than at conventional diesel combustion, presenting higher number of particles from nucleation mode than from accumulation mode.

Dual-Mode Dual-Fuel concept may present a different behavior for particle distribution with respect to the conventional diesel combustion or the traditional low temperature concepts due to the nature of the particles. The objective of the present study is to measure the particle size distribution as well as gaseous emissions of this new DualMode Dual-Fuel concept from low load to full load for a representative engine speed of $1200 \mathrm{rpm}$.

Main results of this study suggest that Dual-Mode Dual-Fuel concept promotes higher quantity of particles than conventional diesel combustion despite of providing less smoke. In addition, nucleation mode particles dominate the particle size distribution for the new combustion concept at low load and moves towards accumulation mode domination at full load.
\end{abstract}




\section{Keywords}

Reactivity controlled compression ignition; Dual-fuel combustion; Particle matter; EURO $\mathrm{VI}$ emissions; Low temperature combustion

\section{Introduction}

High thermal efficiency in reciprocating engines is one of the targets for the engine manufacturers. Compression ignition $(\mathrm{Cl})$ engines provide high thermal efficiency as well as low fuel consumption. Diesel fueled engines have been deeply investigates by the research community [1][2]. Despite the benefits of the conventional diesel combustion $(C D C)$ strategy, several well-known challenges are still persistent due to the mixture stratification [3][4]. The trade-off between nitrogen oxides (NOx) and soot impossibilities the reduction of both emission pollutants simultaneously. In order to meet current emissions regulations such as EURO VI, engine manufacturers have developed aftertreatment systems which drastically reduce theses emissions. Aftertreatment elements imply an increase in the engine cost and operational costs along the engine life.

In order to solve the challenges of the diesel fueled engines, several new compression ignition combustion strategies have been proposed to reduced NOx and soot simultaneously while thermal efficiency is improved [5][6]. Low temperature combustion (LTC) strategies are the most promising combustion modes to avoid the trade-off between NOx and soot [7]. In this sense, homogeneous charge compression ignition $(\mathrm{HCCl})$ virtually avoids any NOx and soot formation [8]. On the other hand, new challenges appear such as pressure rise rate due to the rapid heat release, which limits the concept to the partial load range [9]. Bessonette et al. [10] proposed to use different in-cylinder reactivity with the aim of improving the $\mathrm{HCCl}$ operation on the engine. High engine load requires low cetane number and low load requires high cetane number. Following this guideline and trying to face the challenges presented by the CDC mode and discovered at the LTC strategies, the use of low cetane number (gasoline-like fuels) was extended in strategies such as Partially Premixed combustion (PPC) [11]. Investigations suggest that PPC strategy is better method to control the heat release and, at the same time, maintains the benefits of the LTC strategies with low levels of NOx and soot emissions. By contrast, this concept presents difficulties at low load when a higher than 90 octane number (ON) is used [12]. PPC concept was deeply studied in order to improve the cycle-to-cycle variation at low loads by adding spark assistance [13]. PPC spark assisted was capable to operate with higher ON. However, the spark plug requires local rich equivalence ratios at the start of the spark timing to promote the flame propagation. As a consequence, NOx and soot emissions were unacceptable [14]. Inagaki et al. [15] used different ignitability fuels in order to control the combustion under PPC mode. Isooctane fuel was supplied by a port fuel injection (PFI) system and diesel fuel was injected by a direct injection (DI) system. Results provided by the study, show low values of NOx and soot emissions while the efficiency was improved (over $50 \%$ of gross indicated efficiency). Due to the use of two fuels, the start of the combustion process was possible to be managed by modifying the reactivity of the fuel blend. Kokjohn et al. [16] named this combustion strategy as reactivity controlled compression ignition ( $\mathrm{RCCl})$. $\mathrm{RCCl}$ presents the potential to overcome the most important challenges observed with the LTC strategies [17]. RCCI has been investigated in order to explore the 
capabilities of the concept [18] as well as the effect of the mixture reactivity [19][20]. Additional studies regarding the optimal compression ratio [21] or optimum piston design [22][23][24] were carried out in order to develop a strategy to allow the concept to reach the full engine map [25]. $\mathrm{RCCl}$ has demonstrated to be capable to operate between $10 \%$ engine load up to $80 \%$ engine load respect CDC mode while the NOx emissions were below EURO VI levels [26]. Nonetheless, $\mathrm{RCCl}$ also presents some challenges such as excessive levels of carbon monoxide and unburned hydrocarbons and excessive pressure rise rate at full load.

Aimed to extend the dual fuel operation up to full load with a reduced area of high carbon monoxide (CO) and hydrocarbons ( $\mathrm{HC}$ ) emissions the authors proposed the Dualmode dual- fuel (DMDF) combustion [27]. DMDF combines fully RCCl strategy at low load with dual-fuel combustion strategies as the load is increased by moving diesel injection (from more advanced to more retarded) and, thereby reducing the fuel premixing blend which turns the combustion behavior more diffusive-like. The potential of this concept is found on the optimum control of the combustion allowing to increase the engine load without exceeding the pressure rise rate remaining the thermal efficiency in levels of $\mathrm{RCCl}$ operation mode.

Current standard emissions regulation has introduced a new limitation regarding the number of particles and the particle size distribution (PSD). Particles from $\mathrm{Cl}$ engines are mainly formed by carbon, and particle measurements are usually mass-based. In order to improve the understanding of the particulate matter (PM) emissions from CDC engines, several studies have been performed to obtain the particle size distribution [28][29]. Kittelson et al. [28] described the particle size distribution (PSD) of CDC operation mode as presenting a bimodal shape. Particles are divided in two modes, nucleation mode and accumulation mode. Nucleation mode contains the smaller particles $(D<50 \mathrm{~nm})$ and accumulation mode the larger ones $(D>50 \mathrm{~nm})$. Nucleation mode particles are mainly formed by volatile organic and sulfur compounds, and some studies associate also ashes derived from the oil to this kind of particles [29]. Particles belonging to the accumulation mode provide the most part of the carbonaceous PM emissions. Kittelson et al. [28] stated that nucleation mode particles would represent less than the $20 \%$ of the PM mass emissions but may contain up to $90 \%$ of the total number of particles. Additional studies by using ethanol-diesel and ethanol-biodiesel blends were carried out by Armas et al. [30][31] and were compared to diesel fueled only. Armas et al. stated that the use of oxygenated fuels provide a reduction in the number and size of the accumulation mode particles while the nuclei mode particles increased maintaining constant the scanning mobility diameter. Considering the total number of particles and the total mean diameter decreased when fuel blends were used.

From the particle matter at $\mathrm{RCCl}$ mode standpoint, their speciation results indicate that the high boiling range of diesel hydrocarbons was likely responsible for the particulate matter mass captured on the filter media [32]. Prikhodko et al. [33] found that RCCl was highly dominated by nucleation mode particles. Several studies confirm that RCCI produces lower number of particles amongst other LTC strategies [34][35]. Kolodziej et al. [36] also studied the effects of the diesel proportion and the injection timings in the particle size while operating under RCCl. Zhang et al. [37] stated that LTC have very similar PSD shapes characterized by smaller sized particles. Prikhodko et al. [33] also 
compared the results of FSN and PM filter mass measurements under RCCl operation mode, showing that RCCI PM is mostly organic carbon with almost no elemental carbon. Despite of having some correlations between FSN measurement and soot mass for premixed-charged compression ignition ( $\mathrm{PCCl}$ ) operation [38], for $\mathrm{RCCl}$ is not possible to convert FSN in PM because most part of the PM comes from soluble organic fraction, which is not captured by the smokemeter [39]. Since the Dual-Mode Dual-Fuel combustion mode relies on premixed combustion in the major portion of the engine map, this behavior should be also studied. Thus, the objective of the present study is to explore the gaseous emissions and particle size distribution (PSD) of the DMDF concept and compare them with CDC mode.

\section{Experimental setup}

\subsection{Test cell and engine description}

A single-cylinder derived from a multi cylinder compression ignition engine has been used to study the Dual-Mode Dual-Fuel (DFDM) mode. The engine consists of a stock medium-duty engine. In particular, a four in-line cylinders Volvo engine which meets EURO VI regulation standard. Thus, a dedicated work was made to split the engine in two parts with the aim of isolating one cylinder of the rest of the engine. As it can be observed in the figure 1 , the aftertreatment elements were removed and the first cylinder was isolated from the rest of the engine.

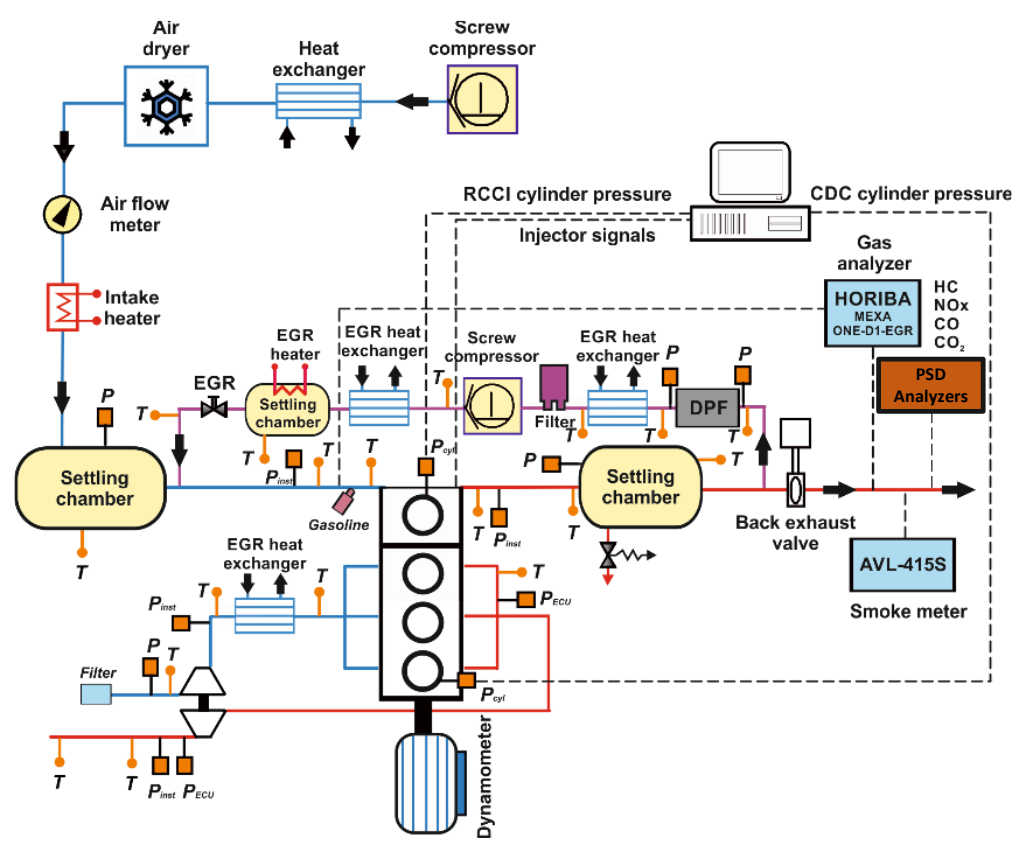

Figure 1. Test cell scheme and engine platform. 
The main characteristics of the engine platform are presented in the table 1 . The engine has been used previously in other studies and is fully described in Benajes et al. [40].

Table 1. Main characteristics of the Volvo engine used.

\begin{tabular}{|l|c|}
\hline Style & 4 Stroke, 4 valves, DI diesel engine \\
\hline Manufacturer / model & VOLVO / D5K240 \\
\hline OEM ECU calibration & EURO VI \\
\hline Piston bowl geometry & Re-entrant \\
\hline Maximum power & 177 kW @ 2200 rpm \\
\hline Maximum brake torque & $190 \mathrm{bar}$ \\
\hline Maximum in-cylinder pressure & $2000 \mathrm{bar} / 3$ \\
\hline $\begin{array}{l}\text { Maximum injection pressure/No } \\
\text { injections }\end{array}$ & $110 \mathrm{~mm} \times 135 \mathrm{~mm}$ \\
\hline Bore x Stroke & $212.5 \mathrm{~mm}$ \\
\hline Connecting rod length & $67.5 \mathrm{~mm}$ \\
\hline Crank length & $5100 \mathrm{~cm}$ \\
\hline Total displaced volume & 4 \\
\hline Number of cylinders & $15.3: 1$ \\
\hline Compression ratio & \\
\hline
\end{tabular}

The main advantage of using a single-cylinder instead of a multi-cylinder is the precise control of the engine variables. By using an isolated cylinder, the cylinder-to-cylinder dispersion is avoided, which allows to measure accurately the exhaust emissions measurements and correlate them directly with the conditions of the combustion chamber.

DMDF injection system consists of a double injector scheme. A port fuel injection (PFI) for the gasoline injection was mounted at the intake manifold and the stock direct injection (DI) system was used to introduce the diesel fuel directly to the cylinder. Both injections were controlled by a National Instruments Drivven software. The gasoline start of injection was set 10 CAD after the intake valve opening (IVO) with the aim of avoiding fuel pooling. The specifications of the diesel injector are presented in the table 2.

Table 2. Main properties of the diesel fuel injector.

\begin{tabular}{|l|c|}
\hline Actuation type & Solenoid \\
\hline Steady flow rate @ 100 bar $\left[\mathrm{cm}^{3} / \mathrm{min}\right]$ & 1300 \\
\hline Number of Holes & 7 \\
\hline Hole diameter $[\mu \mathrm{m}]$ & 177 \\
\hline Included Spray Angle $\left[^{\circ}\right]$ & 150 \\
\hline Maximum injection pressure (bar) & 2000 \\
\hline
\end{tabular}

The properties of the fuel gasoline injector system are presented in table 3.

Table 3. Main properties of the port fuel gasoline injector.

\begin{tabular}{|l|c|}
\hline Injector driver & Saturated \\
\hline Steady flow rate @ 3 bar $\left[\mathrm{cm}^{3} / \mathrm{min}\right]$ & 980 \\
\hline Included spray angle $\left[^{\circ}\right]$ & 30 \\
\hline Injection pressure $[\mathrm{bar}]$ & 5.5 \\
\hline Injection strategy & Single \\
\hline Start of injection timing & 340 CAD ATDC \\
\hline
\end{tabular}


The fuels used through the engine test campaign were ultra-low sulfur diesel (ULSD) EN 590 and 95 octane (RON) gasoline. Both fuels are presented in table 4.

Table 4. Physical and chemical properties of the fuels used along this study.

\begin{tabular}{|l|c|c|}
\cline { 2 - 3 } \multicolumn{1}{c|}{} & Diesel EN590 & 95 \\
\hline Density $\left[\mathrm{kg} / \mathrm{m}^{3}\right]\left(\mathrm{T}=15^{\circ} \mathrm{C}\right)$ & 820 & 720 \\
\hline Viscosity $\left[\mathrm{mm}^{2} / \mathrm{s}\right]\left(\mathrm{T}=40^{\circ} \mathrm{C}\right)$ & 2.00 & 0.47 \\
\hline RON [-] & - & 95.0 \\
\hline MON [-] & - & 85.0 \\
\hline Cetane number [-] & $>51$ & - \\
\hline Lower heating value $[\mathrm{MJ} / \mathrm{kg}]$ & 42.97 & 42.4 \\
\hline
\end{tabular}

Fuels were measured with two AVL 733S flowmeters, which operates by weighting with a gravimetrical balance the total amount of fuel injected in the engine.

Emissions were measured with a five gas Horiba MEXA-ONE-D1-EGR analyzer. The equipment acquired $\mathrm{NOx}, \mathrm{CO}$, unburned $\mathrm{HC}$, intake and exhaust $\mathrm{CO}_{2}$ and oxygen $\left(\mathrm{O}_{2}\right)$ concentration. In addition, smoke emissions were obtained by using an AVL 415S Smoke Meter providing results directly in FSN (Filter Smoke Number) units.

In-cylinder pressure was measured with a Kistler $6125 \mathrm{C}$ pressure transducer together with a Kistler 5011B10 charge amplifier. An 1800 pulses per revolution shaft encoder was used to measure the crank angle degree (CAD), providing a resolution of 0.2 CAD. The pressure traces were recorded from 300 cycles for compensating the possible cycleto-cycle dispersion during the engine operation.

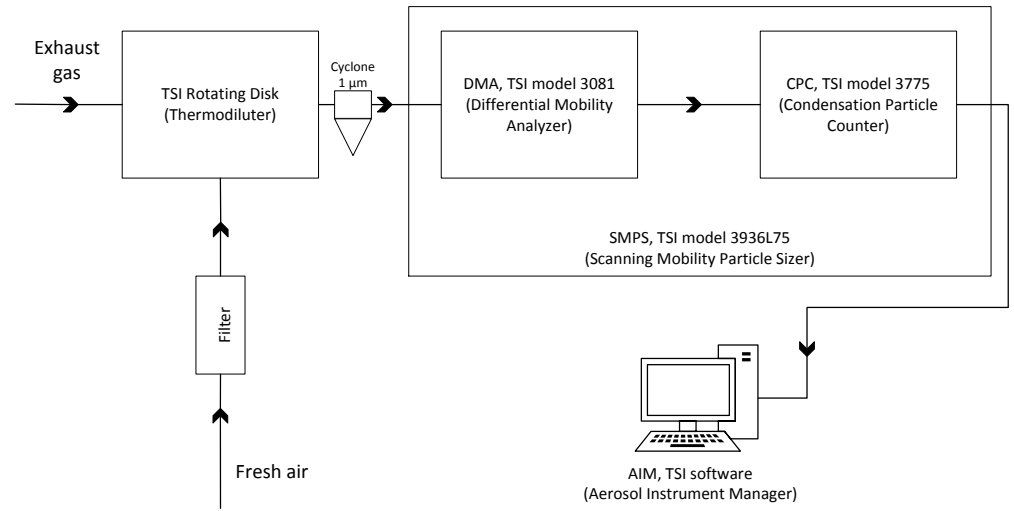

Figure 2. Scheme of the PSD analyzer equipment.

In figure 1 is presented a scheme of the test bench and the PSD equipment location. All of the elements used for the PM data acquisition such as the thermodiluter, the scanning mobility diameter and the condensation particle counter, are presented in the figure 2

As depicted in figure 2, particulate size was sampled downstream the backpressure valve, which is located after the settling exhaust chamber. The equipment used to measure the particulate matter consist of a diluter, a scanning mobility particle sizer (SMPS) and a condensation particle counter (CPC). The diluter is a thermodiluter TSI Rotating Disk. The equipment dilutes the sample using the rotating disk method. Each unit is supplied with two disks which are prepared with different number of cavities each disk. Then, a raw portion of the exhaust flow is captured by the cavities and is conducted 
through the mixer with particle-free air. This method provides high precision and great stability. In order to avoid measuring the condensates from the volatile elements, the air must be heated avoiding thereby nanodroplets formation, which are detected as particles also. Dilution of the exhaust gases is required to adapt the particulate inlet concentration for the SMPS. In the present study, the dilution ratio selected was 90:1, and in order to avoid volatiles condensation, the diluted sample was heated up to 150 ${ }^{\circ} \mathrm{C}$.

The SMPS (TSI model 3936L75) system is formed mainly by the Differential Mobility Analyzer (DMA, TSI model 3081) and the Condensation Particle Counter (CPC, TSI model 3775). DMA equipment method is based on the physical principle that the ability of a particle to cross an electric field is directly related to particle size. Once the particle sample is sized by the DMA, it is measured using a condensation particle counter (CPC, TSI model 3775). The system has been configured to count particles between 5 to 250 $\mathrm{nm}$. The Aerosol Instrument Manager (AIM, TSI) software acquires high-resolution data and process the particulate size distribution (PSD) data. The accuracy of the instrumentation used in the test cell is summarized in table 5.

Table 5. Accuracy of the instrumentation used in the test cell.

\begin{tabular}{|l|l|l|l|}
\hline Variable measured & Device & Manufacturer / model & Accuracy \\
\hline In-cylinder pressure & $\begin{array}{l}\text { Piezoelectric } \\
\text { transducer }\end{array}$ & Kistler / 6125C & \pm 1.25 bar \\
\hline Intake/exhaust pressure & $\begin{array}{l}\text { Piezorresistive } \\
\text { transducers }\end{array}$ & Kistler / 4045A10 & \pm 25 mbar \\
\hline $\begin{array}{l}\text { Temperature in settling } \\
\text { chambers and manifolds }\end{array}$ & Thermocouple & TC direct / type K & $\pm 2.5^{\circ} \mathrm{C}$ \\
\hline Crank angle, engine speed & Encoder & AVL / 364 & \pm 0.02 CAD \\
\hline NOx, CO, $\mathrm{HC}, \mathrm{O}_{2}, \mathrm{CO}_{2}$ & Gas analyzer & HORIBA / MEXA-ONE-D1-EGR & $4 \%$ \\
\hline FSN & Smoke meter & AVL / 415S & $\pm 0.001 \mathrm{FSN}$ \\
\hline Particles number and size & SMPS & TSI / 3936L75 & $3.5 \%$ \\
\hline $\begin{array}{l}\text { Gasoline/diesel fuel mass } \\
\text { flow }\end{array}$ & Fuel balances & AVL / 733S & $\pm 0.2 \%$ \\
\hline Air mass flow & Air flow meter & Elster / RVG G100 & $\pm 0.1 \%$ \\
\hline
\end{tabular}

\subsection{Testing procedure. Test matrix}

This section explains the guidelines followed in order to achieve Dual-Mode Dual-Fuel (DMDF). DMDF is based on three injection strategies such as fully premixed, highly premixed and partially premixed which lead into two combustion modes, $\mathrm{RCCl}$ with ultra-low NOx and low smoke emissions and Dual-Fuel mode where NOx and smoke limits are not as stringent as for $\mathrm{RCCl}$. Up to medium-high load is fully/highly premixed, whereas from medium-high to full load is mainly diffusive. To control the in-cylinder reactivity, two fuels are used. The combustion modes are used as a function of the engine load desired. In table 6 , it is presented the modes and the engine load range where is applied. 
Table 6. Engine load and combustion mode classification.

\begin{tabular}{|c|c|c|c|}
\hline \multicolumn{4}{|c|}{ Dual-Mode Dual-Fuel (DMDF) } \\
\hline & \multicolumn{2}{|c|}{ Engine load } & Mixing degree \\
\hline Mode & $\%$ & $\begin{array}{c}\text { IMEP } \\
\text { (bar) }\end{array}$ & {$[-]$} \\
\hline $1 . a$ & $10-40$ & $3-6$ & Fully \\
\hline $1 . b$ & $40-75$ & $6-17$ & Highly \\
\hline 2 & $75-100$ & $17-22$ & Partially \\
\hline
\end{tabular}

Mechanical limitations defined by the engine manufacturer, such as maximum pressure rise rate and maximum in-cylinder pressure, restrict the operation range of the $\mathrm{RCCl}$ concept. As presented in table 7, the constraints of each operation mode are classified in mechanical and emissions limitations.

Table 7. Combustion modes constraints.

\begin{tabular}{|c|c|c|c|c|}
\hline \multicolumn{5}{|c|}{ Dual-Mode Dual-Fuel (DMDF) } \\
\hline & \multicolumn{2}{|c|}{$\begin{array}{l}\text { Mechanical } \\
\text { Constraints }\end{array}$} & \multicolumn{2}{|c|}{$\begin{array}{l}\text { Emissions } \\
\text { Constraints }\end{array}$} \\
\hline Mode & $\begin{array}{c}\text { In-cylinder pressure } \\
\text { (bar) }\end{array}$ & $\begin{array}{c}\text { PRR } \\
\text { (bar/CAD) }\end{array}$ & $\begin{array}{c}\text { NOx } \\
\text { (g/kWh) }\end{array}$ & $\begin{array}{c}\text { Smoke } \\
\text { (FSN) }\end{array}$ \\
\hline 1.a & \multirow{3}{*}{190} & \multirow{3}{*}{15} & $<0.4$ & $<0.5$ \\
\hline $1 . b$ & & & $<0.4$ & $<1.5$ \\
\hline 2 & & & $>0.4$ & $<3$ \\
\hline
\end{tabular}

As figure 3 shows, each combustion mode provides a different rate of heat release. Injection settings are also depicted in order to clarify the start of injection (Sol) of both fuels and the number of injections. It is worthy to note that gasoline is always injected at -340 ATDC. Mode 1.a is fully premixed, used at low load, in which both fuels are injected very advanced from the top dead center (TDC) and the combustion duration is short (around 20 CAD). The RoHR presents an inverted V-shaped curve in the figure. Mode 1.b is a highly premixed strategy, is depicted on the second graph and it has moved the second diesel injection. Despite there is a lot of premixing, the second injection ignites the combustion. Thus, the last part of the RoHR has some diffusive trends and, thereby the combustion duration is slower than for fully premixed mode (36 CAD for fully premixed vs 48 CAD for highly premixed). Mode 2 is used at high engine load. The most relevant variation with respect to the other modes is that there is only 1 diesel injection, and this one determines the ignition of the combustion. In figure 3 is observed the RoHR two-peaked curve, starting with a high peak due to the gasoline combustion due to the first diesel reactions and a second diesel-like peak which could 
correspond to the major part of diesel and gasoline traces showing a mainly diffusive nature of the combustion.
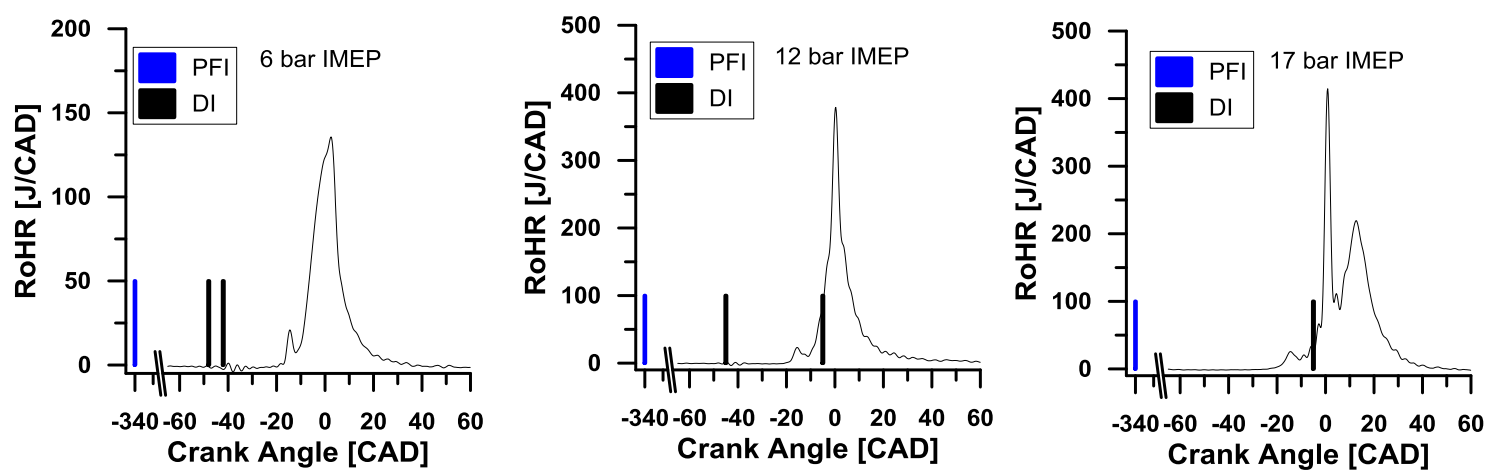

Figure 3. Rate of heat release and injection timings for DMDF.

Once DMDF strategy was explained, the testing procedure to achieve is presented. Thus, three steps are considered. Firstly the engine is driven to the desired engine load and stabilized. First step is critical due to mechanical constraints exposed in table 7 must not be exceeded (PRR, $P_{\max }$ and emissions). In order to reach the desired load, injection settings such as the Sol and the gasoline fraction (GF) must be adjusted properly. Once a stable operation is achieved, starts the second step. This step guarantees not to exceed NOx and smoke emissions limitations. In this step, the adjustments of the GF (equation 1 shown below), diesel injection timing and EGR rate must be used. The gasoline fraction determines the reactivity of the fuel blend, which controls the ignition of the combustion, obtaining the desired combustion phasing (CA50). Thus, adding gasoline the gasoline fraction will increase and the reactivity of the fuel will decrease moving the CA50 to a more delayed position respect the TDC and vice versa.

$$
G F[\%]=\frac{m_{\text {Gasoline }}}{m_{\text {Diesel }}+m_{\text {Gasoline }}}
$$

Where mgasoline is the fuel mass of the gasoline and mdiesel is the fuel mass of the diesel.

The next step consists of a raw optimization in order to reduce $\mathrm{CO}$ and unburned $\mathrm{HC}$ by adjusting the EGR rate and diesel Sol mainly. In this sense, the aim of the last step is to improve the combustion at the desired operation point and, thereby reduce fuel consumption.

The different cases performed in this study were carried out at the engine speed of 1200 rpm. Table 8 presents the test matrix used at this study. There, it is shown the indicated mean effective pressure (IMEP), the engine load, the injection settings, combustion phasing and the injection pressure for CDC and DMDF combustion modes. 
Table 8. DMDF and CDC settings @ 1200 rpm.

\begin{tabular}{|c|c|c|c|c|c|c|c|}
\hline \multicolumn{8}{|c|}{ Dual-Mode Dual-Fuel (DMDF) } \\
\hline \multirow[t]{2}{*}{ Modes } & IMEP & Load & Sol 1 & Sol 2 & Sol PFI & CA50 & $\begin{array}{l}\text { Inj. } \\
\text { Pres. }\end{array}$ \\
\hline & bar & $\%$ & $(C A D)^{\circ} a T D C$ & $(C A D)^{\circ} a T D C$ & $(C A D)^{\circ} a T D C$ & $(C A D)^{\circ} a T D C$ & (bar) \\
\hline \multirow{2}{*}{$\begin{array}{c}\text { Fully } \\
\text { premixed } \\
(1 . a)\end{array}$} & 3 & 10 & -40 & -33 & \multirow{5}{*}{340} & -2 & \multirow{5}{*}{1200} \\
\hline & 6 & 25 & -48 & -42 & & 1 & \\
\hline $\begin{array}{c}\text { Highly } \\
\text { premixed } \\
(1 . b)\end{array}$ & 12 & 50 & -45 & -5 & & 1.5 & \\
\hline \multirow{3}{*}{$\begin{array}{c}\text { Mainly } \\
\text { diffusive (2) }\end{array}$} & 17 & 75 & - & -2 & & 9.5 & \\
\hline & 22 & 100 & - & 6 & & 12.7 & \\
\hline & \multicolumn{7}{|c|}{ Conventional Diesel Combustion (CDC) } \\
\hline \multirow{5}{*}{$\mathrm{CDC}$} & 3 & 10 & -5 & 1 & \multirow{5}{*}{-} & 10 & 1120 \\
\hline & 6 & 25 & -2 & 5 & & 17 & \multirow{4}{*}{1200} \\
\hline & 12 & 50 & -5 & 3 & & 17 & \\
\hline & 17 & 75 & -9 & -1 & & 15 & \\
\hline & 22 & 100 & -10 & -4 & & 14 & \\
\hline
\end{tabular}

Additional settings regarding the engine air management are shown in the table 9 such as the boost pressure, exhaust back pressure, EGR rate and the gasoline fraction (GF). EGR was calculated using an experimental measurement of intake and exhaust carbon dioxide $\left(\mathrm{CO}_{2}\right)$ concentration. The equation used is shown below (2). Additionally, the symbols used are also detailed.

$$
\mathrm{EGR}[\%]=\frac{\mathrm{CO}_{2 \mathrm{int}}-\mathrm{CO}_{2 \mathrm{amb}}}{\mathrm{CO}_{2 \mathrm{exh}}-\mathrm{CO}_{2 \mathrm{amb}}}
$$

Where $\mathrm{CO}_{2 \text { int }}$ is the $\mathrm{CO}_{2}$ concentration measured at the inlet manifold; $\mathrm{CO}_{2 \text { exh }}$ represents the $\mathrm{CO}_{2}$ concentration measured at the exhaust manifold and $\mathrm{CO}_{2 a m b}$ refers to the $\mathrm{CO}_{2}$ concentration at the ambient.

Table 9. Air management settings for both modes @ 1200 rpm.

\begin{tabular}{|c|c|c|c|c|c|c|}
\hline \multicolumn{6}{|c|}{ DMDF } & \\
\hline IMEP & Load & Boost pressure & Exhaust pressure & EGR rate & GF & $\begin{array}{l}\text { Int. } \\
\text { temp }\end{array}$ \\
\hline bar & $\%$ & bar & bar & $\%$ & $\%$ & ${ }^{\circ} \mathrm{C}$ \\
\hline 3 & 10 & 1.4 & 1.5 & 20 & 60 & \multirow{5}{*}{40} \\
\hline 6 & 25 & 1.6 & 1.7 & 20 & 80 & \\
\hline 12 & 50 & 2.2 & 2.4 & 50 & 62 & \\
\hline 17 & 75 & 3 & 3.2 & 45 & 45 & \\
\hline 22 & 100 & 3 & 3.2 & 30 & 34 & \\
\hline \multicolumn{6}{|c|}{$\mathrm{CDC}$} & \\
\hline 3 & 10 & 1.2 & 1.5 & 30 & \multirow{5}{*}{0} & \multirow{5}{*}{30} \\
\hline 6 & 25 & 1.4 & 1.9 & 20 & & \\
\hline 12 & 50 & 1.8 & 1.9 & 4.5 & & \\
\hline 17 & 75 & 2.4 & 2.5 & 0 & & \\
\hline 22 & 100 & 2.5 & 2.4 & 0 & & \\
\hline
\end{tabular}




\section{Combustion analysis}

Figure 4 presents the main results in terms of combustion process such as the in-cylinder pressure, rate of heat release (RoHR) and bulk gas temperature for both operating modes. Additional figures have been included to better describe the combustion process understanding. Figure 5 presents the maximum in-cylinder pressure $\left(P_{\max }\right)$ and the pressure rise rate (PRR). And figure 6 shows the CA10 (CAD when 10\% of the fuel mass is burnt), the CA90 (CAD where the $90 \%$ of the fuel mass is burnt), the duration of the combustion (CA90-CA10) and the mixing time (CA10-Eol).
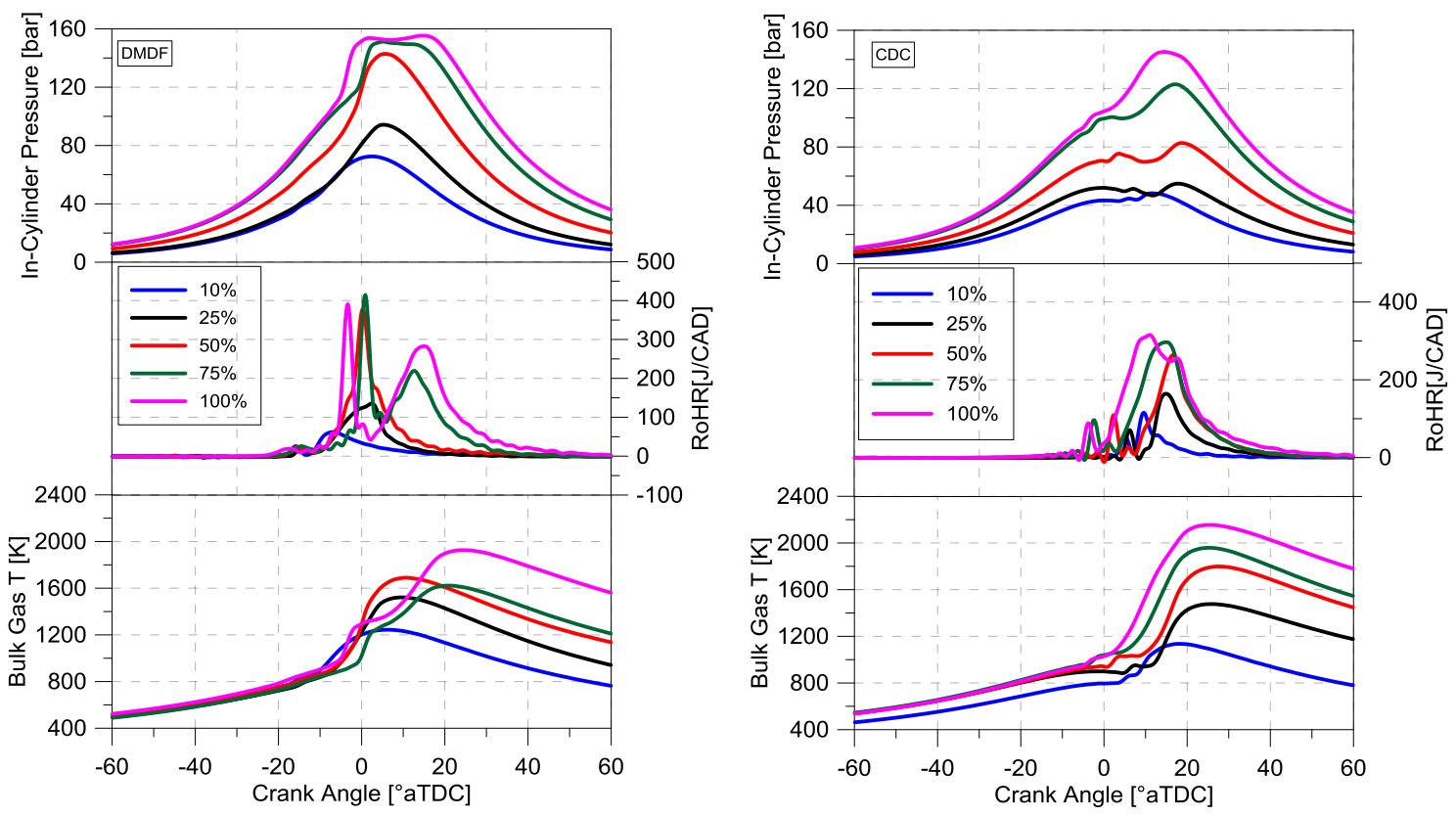

Figure 4. In-cylinder pressure, rate of heat release and bulk gas temperature for DMDF (left) and CDC (right).

From the figure 4 (left), DMDF fully premixed strategy goes from $10 \%$ to $40 \%$ engine load ( 3 bar and 6 bar IMEP) and DMDF highly premixed strategy is used between $40 \%$ and $75 \%$ (12 bar IMEP). Green colored lines show DMDF mainly diffusive (75\% to $100 \%$ ) curves.

DMDF fully premixed strategy presents higher in-cylinder pressure curves than CDC. From figure 5, it is observed that the maximum pressure achieved as well as the pressure gradient are below the constraint imposed. At $10 \%$ engine load, despite of having higher maximum in-cylinder pressure and higher pressure rise rate, the RoHR presents a lower peak of energy as well as a slower combustion process. This can be observed in figure 5 at the CA90-CA10 graph. Nonetheless, at $25 \%$ engine load, presents similar in-cylinder temperature, higher maximum pressure and higher PRR than CDC. In addition, figure 6 shows the combustion duration and, in this case, DMDF is faster than CDC. In figure 6 is also presented the mixing time, which is higher for DMDF than CDC at both engine loads. This confirms the premixed behavior of the DMDF respect the diffusive combustion of CDC. 


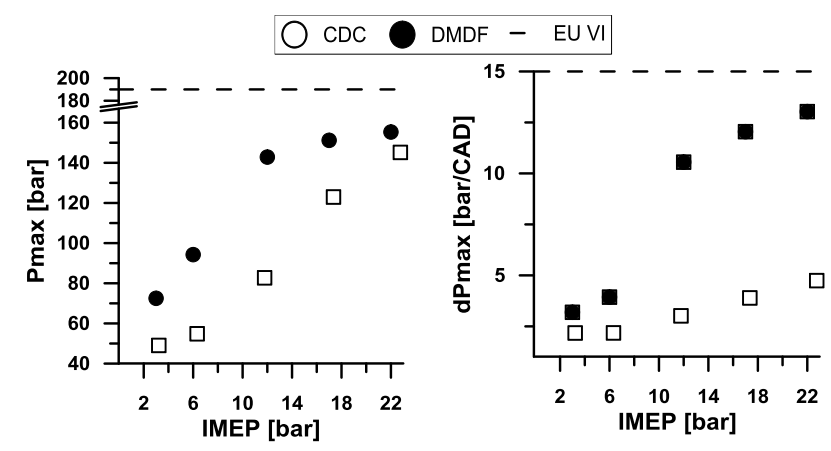

Figure 5. Maximum in-cylinder pressure and pressure rise rate.

DMDF highly premixed corresponds to $50 \%$ engine load. This strategy also presents higher in-cylinder pressure than CDC mode. Regarding the RoHR, presents a higher peak than $C D C$, and the maximum PRR and the maximum in-cylinder pressure are higher than CDC also, while remain below the imposed constraints. At the end-part of the RoHR can be appreciated some diffusive trend due to the variation of the second injection timing towards the TDC. In figure 6, the mixing time observed for 12 bar IMEP is the highest of the studied points. Despite of moving the second injection to improve the control of the combustion process, the premixing of the strategy is preserved.

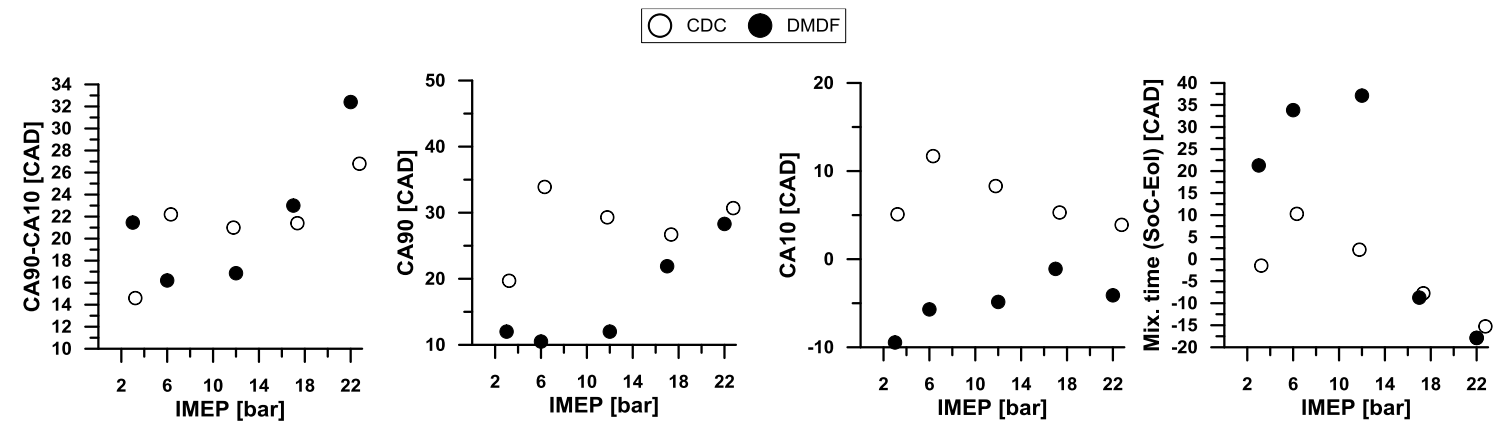

Figure 6. Combustion phasing and mixing time for both operation strategies.

DMDF mainly diffusive is characterized by having only one diesel injection close to the TDC in order to improve the control of the combustion. However, the RoHR curve for $75 \%$ and $100 \%$ engine load presents a two-peaked curve for the gasoline and diesel combustion. The two-peaked curve shows a first peak of about 5 CAD of duration and $400 \mathrm{~J} / \mathrm{CAD}$ and a second peak (about $30 \mathrm{CAD}$ ) of $300 \mathrm{~J} / \mathrm{CAD}$. Therefore, the PRR is much higher than $C D C$ mode and the in-cylinder pressure presents a flat curve. The second part of the RoHR shows a clear diffusive behavior along the combustion process. The similar mixing time, respect the CDC strategy, and the diffusive behavior acquired due to the diesel injection provide a large combustion duration as it can be observed in at the CA90-CA10 graph of figure 6.

\section{Emissions analysis}

This section describes the emissions divided in two subsections. The first one focuses on the gaseous nature of the exhaust emissions such as NOx, CO and unburned HC. The second focuses on the study of the smoke emissions and the particles size distribution. 


\subsection{Gaseous Emissions}

This subsection describes the results of the exhaust emissions comparison between CDC and DMDF operation modes. NOx, CO and unburned HC emissions obtained are depicted in figure 7. With the aim of completing the data of the emissions analysis, figure 8 shows the gasoline fraction (GF), EGR rate, intake pressure, number of injections and injection timings.

The main characteristics of the DMDF operation mode is that it promotes less NOx for all the loads than CDC. Indeed, NOx values remain below EURO VI limitation up to 17 bar IMEP (75\% load). This low NOx emissions should be possible due to the lower in-cylinder gas temperatures reached which avoid NOx formation, as it is observed in figure 4 (left). Lower in-cylinder temperatures are obtained by using high EGR rates (up to 50\%) and high levels of gasoline in the fuel mixture (up to $85 \%$ of GF).
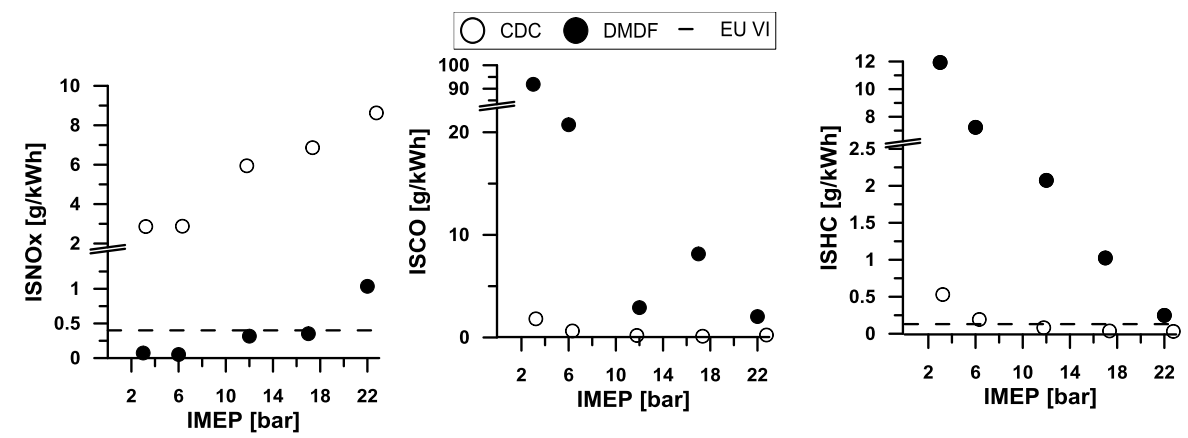

Figure 7. NOx, smoke, CO and unburned HC emissions for DMDF and CDC.

On the other hand, $\mathrm{CO}$ and unburned $\mathrm{HC}$ emissions are much higher than for $\mathrm{CDC}$ mode. At low load, unacceptable levels were found. $\mathrm{CO}$ and unburned $\mathrm{HC}$ emissions measured at lower loads ( 3 and 6 bar IMEP) are produced due to the low in-cylinder temperatures achieved during the combustion, which confirms the incomplete burning fuel. From 12 bar IMEP to full load, CO and unburned HC values are much lower than at low load. In any case, $\mathrm{CO}$ and unburned $\mathrm{HC}$ levels are higher than the values obtained at CDC operation, as it is observed at figure 7. 

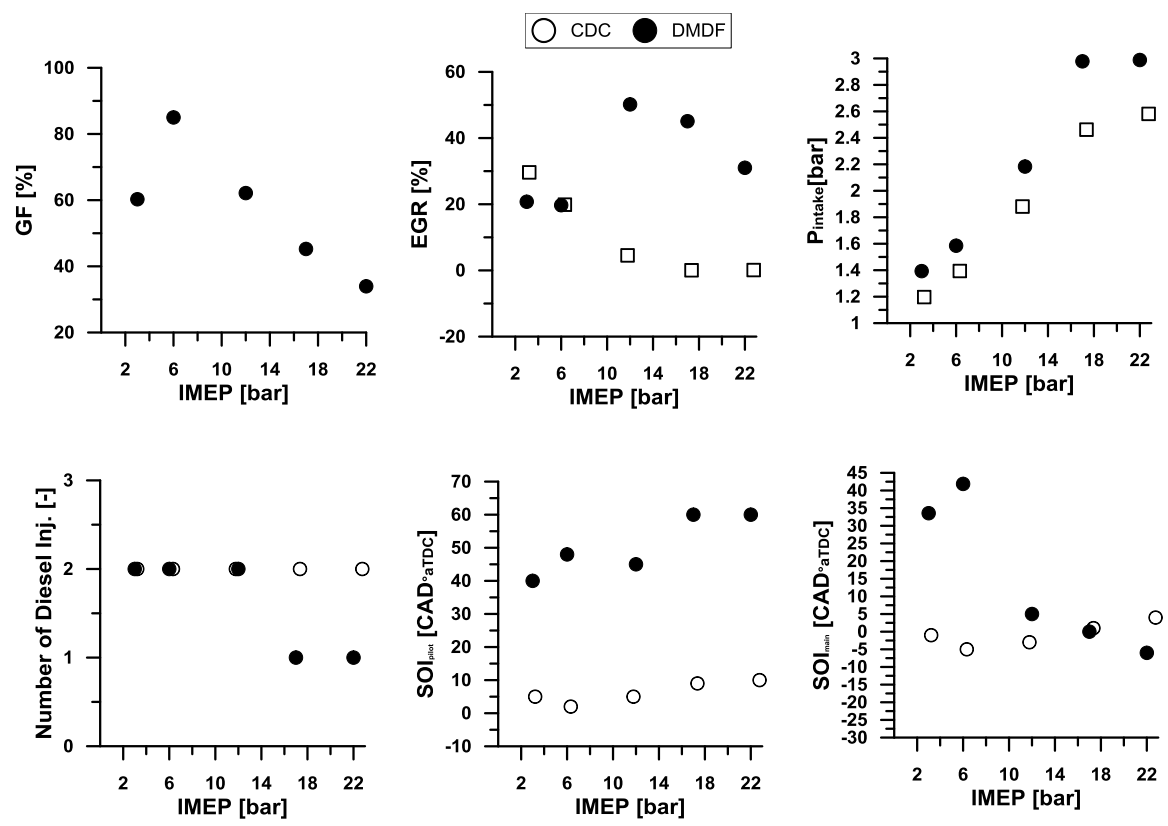

Figure 8. Gasoline fraction (GF), EGR rate, intake pressure, number of injections and injection timings for DMDF and CDC.

\subsection{Smoke, Particle size and Particle Number Emissions}

The present subsection describes the smoke emissions and the particle size distribution obtained for DMDF as well as for CDC. From the smoke emissions stand point, the results are presented in FSN for both operating modes at figure 9.

At low loads, smoke emissions for DMDF fully premixed are very similar than the smoke measured for CDC mode due to the OEM ECU calibration. These values are due to the higher mixing time observed at 3 and 6 bar IMEP for the fully premixed strategy (figure 8).

Regarding CDC case, the low values of FSN measured shown in figure 9 are around 0.12 FSN. This reduced levels are obtained due to a better mixing time as it can be observed at figure 4 (left), where mixing times are around 0 CAD at the lowest load and 10 CAD at 6 bar IMEP are observed. Soot emissions for CDC are very low in this load range due to the ECU manufacturers calibration.

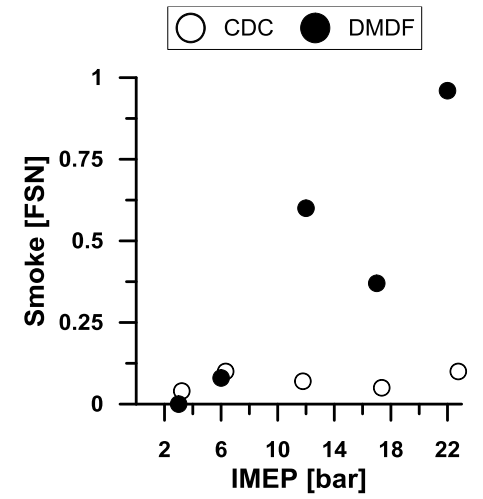

Figure 9. Smoke emissions in FSN for DMDF and CDC. 
At medium engine load (12 bar IMEP), big difference in smoke emissions between DMDF highly premixed and CDC operation mode are observed in figure 9. CDC presents a better mixing time in figure 6 than DMDF, which reduces the local rich equivalence ratios. In addition, the EGR rates used are very low also (figure 8), allowing the oxidation of the soot formed during the combustion process. DMDF highly premixed strategy shows higher levels of smoke than CDC. Despite of having high values of mixing time (40 CAD), which can be observed in figure 6, the massive use of EGR rates (up to 50\%) observed in figure 5 should provoke a richer fuel equivalence ratio due to the lower oxygen available at the combustion chamber, producing soot formation.

At high engine load (from 17 to 22 bar IMEP), smoke emissions for CDC remain lower than for DMDF mainly diffusive operation mode. Low EGR rates allow a better oxidation of the soot formed during the combustion process, resulting in lower values of FSN that the ones observed at low load.

DMDF mainly diffusive produces more smoke than the CDC cases. This behavior is explained due to the combustion nature of the DMDF strategy. Figure 6 shows the mixing time of this strategy, being very similar than the mixing time observed for the CDC cases due to the diffusive nature of the DMDF strategy at high engine load. In addition, CDC cases recirculating exhaust gases ( $0 \%$ EGR rate), DMDF mainly diffusive uses EGR rates up to $40 \%$ as it is depicted in figure 8 . Combination of negative mixing time and high EGR rates produces richer equivalence ratios, what enables soot formation. As a result, FSN measurements are much higher than for CDC.

FSN indicates, as it consists of a sample exhaust filter, the formation of black carbon. But the total amount of particles, including those which are formed by volatile organic species, are not represented with the FSN measurements. Therefore, lower FSN may not indicate lower total amount of particulates [32].

Present section shows the particle size distribution (PSD) measurements of every engine load tested at $1200 \mathrm{rpm}$. Figure 10 shows the total number of particles obtained for each combustion mode. At first sight, it is clearly shown that the quantity or particles between 5-250 $\mathrm{nm}$ is higher for the Dual-Mode concept than for CDC mode.

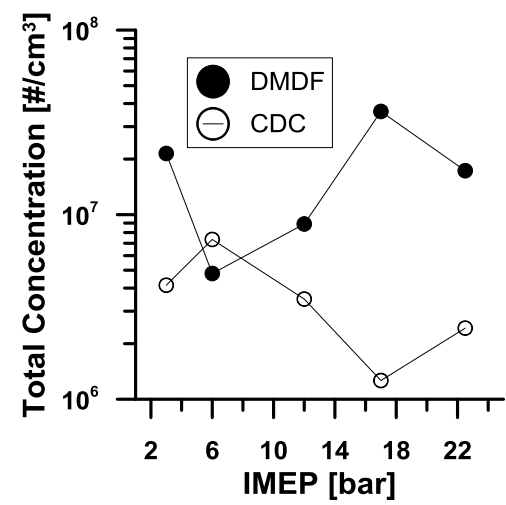

Figure 10. Total number of particles for both combustion modes.

With the aim of improving the understanding of the total particle concentration observed in figure 10, the particle size distribution for both modes have been depicted in figures 11 and 12 . 
Figure 11 contains particle size distribution (PSD) for 10\%, 25\% and 50\% engine load operated under both modes studied. This figure shows the quantity of particles measured respect the mobility diameter of the particles. The PSD observed at low load under CDC operation mode reflects that the particles distribution is governed by the higher sized diameter particles. Under CDC operation, PSD curves present a peak of number of particles at $50 \mathrm{~nm}$ of mobility diameter. In this sense, high sized particles dominate the CDC operation distribution. High sized particles usually refers to carbonaceous particles [41].

Regarding DMDF fully premixed operation, the PSD curve present a dominant peak at $20 \mathrm{~nm}$ and a secondary peak at $80 \mathrm{~nm}$ of mobility diameter. Thus, low sized particles dominate DMDF fully premixed. However, the second peak observed at the DMDF fully premixed PSD curves is probably provoked by the coagulation phenomenon [42]. In this sense, when high number of small particles are formed, some part of the particles can coagulate giving as a result higher diameter particles and, thereby these particles might be not carbonaceous but organic volatile [41]. Hence, these particles would not be detected by the smokemeter providing low measurement FSN values.
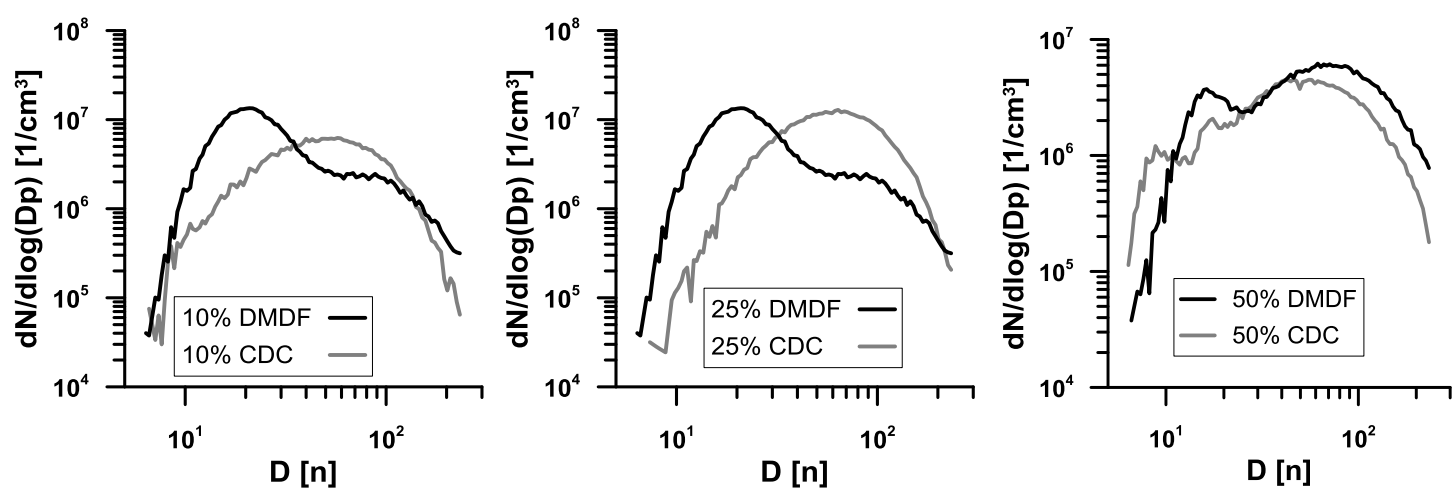

Figure 11. Particle size distribution for DMDF fully and highly premixed and CDC.

DMDF highly-premixed is also presented in figure 11 compared with the CDC curve. CDC curve present a similar trend that the CDC curve observed at $10 \%$ and $25 \%$ engine load. PSD is also dominated by high sized particles around $50 \mathrm{~nm}$ of mobility diameter. DMDF highly-premixed PSD curve presents a bimodal shape. This curve has two peaks with the same order of magnitude. The first peak is observed below $20 \mathrm{~nm}$ of diameter and the second peak is located at the diameter of $70 \mathrm{~nm}$. As the high sized particles observed are carbonaceous, the FSN measurement presents also a peak of 0.6 , as it is observed in figure 9. Despite of the mixing time for 12 bar IMEP in figure 5, the massive use of EGR and the second diesel injection moved closer to the TDC results in the late end combustion similar to the last part of the diffusion combustion. This phenomenon is clearly observed at the RoHR presented in figure 2 for the highly-premixed curve. This combination provides soot formation and, thereby high sized particles production. 
Figure 12 presents the particles size distribution of the DMDF mainly diffusive mode and the CDC operation mode at $75 \%$ and $100 \%$ engine load. Both operation modes are dominated by the high sized particles.
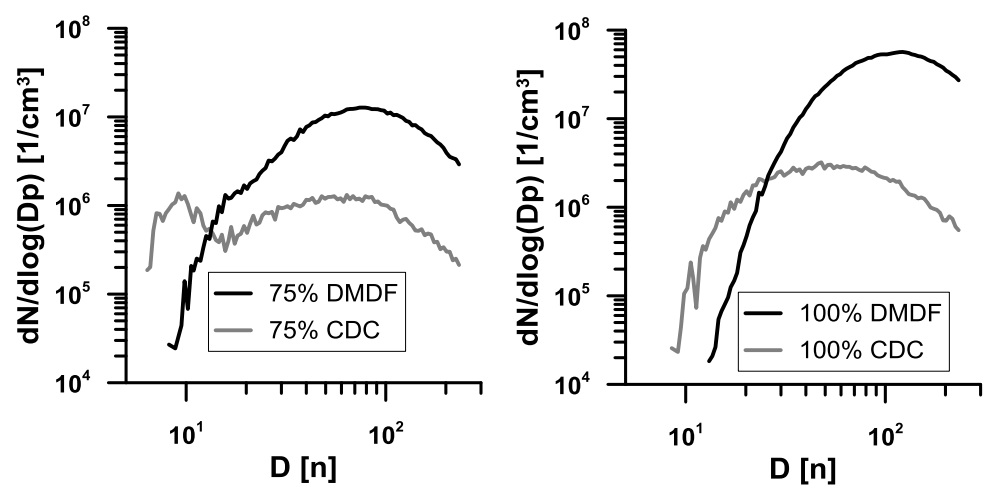

Figure 12. Particle size distribution for DMDF mainly diffusive and CDC.

Comparing both curves, DMDF mainly diffusive mode presents a curve peak at $80 \mathrm{~nm}$ for $75 \%$ engine load and at $100 \mathrm{~nm}$ at full load. CDC PSD curves present a peak at $70 \mathrm{~nm}$ at $75 \%$ engine load and at $50 \mathrm{~nm}$ at full load. For both modes, the size distribution is characterized by such a large particles, which suggests carbon particles. In figure 13, smoke emissions are depicted and the values obtained are clearly correlated with the particle distribution.

Additionally to the PSD study, a classification between nucleation mode and accumulation mode has been carried out in order to try to differentiate the nature of the particles. Therefore, figure 13 presents the total number of particles measured and the classification of nucleation or accumulation mode. Additionally, the soot emissions in terms of FSN have been also added to the graph in order to complete the information scope of the particle emissions.

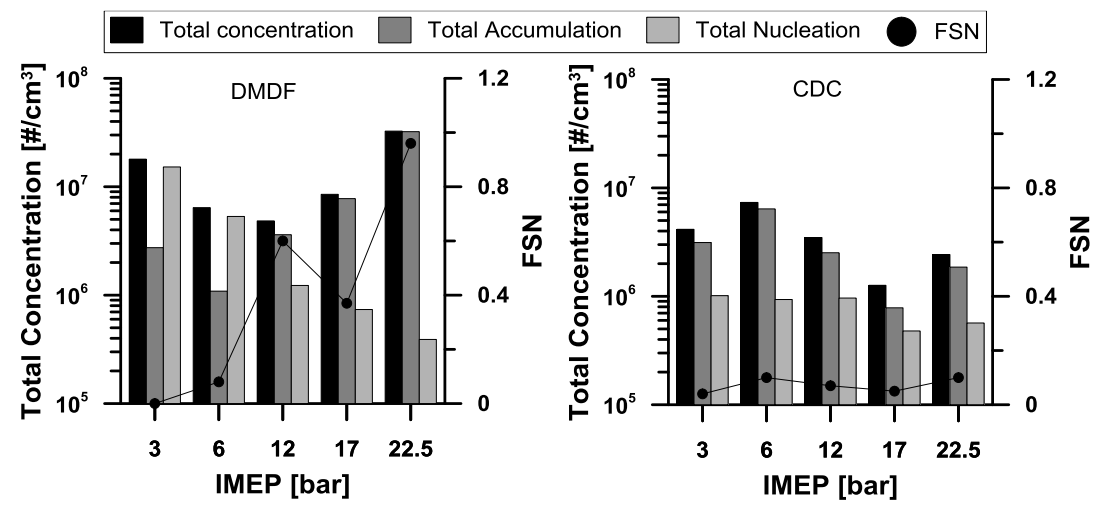

Figure 13. Classification of the nature of the particles and FSN measurements

The criteria followed to classify particles in terms of nucleation mode or accumulation mode is the mobility diameter of the particle. Some authors define the nucleation mode size limit as $30 \mathrm{~nm}$ [41] due to the nature of the particle, which is mainly composed by volatile organic material. The other mode is accumulation, which contains particles between $40 \mathrm{~nm}$ to $1 \mu \mathrm{m}$ in diameter, is mainly formed by soot with hydrocarbons adhered to the surface [41][43]. Figure 13 presents the classification of the particles in 
terms of nucleation or accumulation mode performed for both operation modes as well as the smoke emissions in FSN.

As it is shown in the figures 11 and 12, CDC PSD curves present the peaks of number of particles at the mobility diameter higher than $50 \mathrm{~nm}$ for all the engine load cases studied. As it can be observed in figure 13, the FSN measured is directly related with the total amount of particles measured. The particle cutoff diameter used to limit both fields must be lower than $50 \mathrm{~nm}$ in order to distinguish properly the larger particles mainly formed by soot from the smaller particles mainly formed by volatiles. Therefore, the cutoff diameter selected for the CDC operation mode is $30 \mathrm{~nm}$. In this sense, the number of particles counted of nucleation particles is much lower than the number of accumulation mode particles. In addition, FSN measurements are corresponded with the trend observed by the accumulation mode particles presented in the figure. If FSN increases, the number of accumulation mode particles and, thereby the total number of particle, increases. However, nucleation mode particles remain constant for all the engine load cases.

Regarding the DMDF operation strategy, the particularly for each combustion mode defined in table 6. Hence, two modes were defined as DMDF fully/highly premixed and mainly diffusive strategies. From the PSD analysis, curve peaks have been identified at different mobility diameters. So that, authors consider that the cutoff diameter must be studied for each particular case in order to be as much accurate as possible. Following description tries to explain the criteria followed for the classification.

From the analysis, it is concluded that particles nature are formed by volatiles. In addition, due to the high quantity of small particles, coagulation phenomenon appears and produces a secondary peak at the PSD curve. Therefore, the cutoff diameter for this mode of combustion is $50 \mathrm{~nm}$. In this sense, lower particles are counted as nucleation mode particles and larger particles as accumulation mode particles. As it is observed in figure 13, the FSN values are very low (around 0 at 3 bar IMEP) and the accumulation mode particles also represent a small fraction of the total number of particles. Thus, nucleation mode particles represent the major fraction of the total number concentration of particles. Comparing the total number of particles to CDC, DMDF fully premixed emitted higher number of particles.

DMDF highly premixed mode PSD analysis highlights that the double curve peak obtained presents a bigger quantity of large-sized carbonaceous particles than the previous fully premixed and CDC mode. Thus, the cutoff diameter, since the peaks are observed at $20 \mathrm{~nm}$ and at $70 \mathrm{~nm}$, has been fixed at $30 \mathrm{~nm}$. Thus, nucleation mode particles are those which a lower mobility diameter of $30 \mathrm{~nm}$ and accumulation mode particles are those which mobility diameter is higher than $30 \mathrm{~nm}$. At 12 bar IMEP (50\% load) at figure 13, the highly premixed point shows higher number of accumulation mode particles, which corresponds with a smoke emissions peak. In this sense, large sized particles dominate the particles emission at highly premixed. Despite of having more FSN values than fully premixed mode, the number of particles is lower. This results should be consequence of the particle nature behavior moving from nucleation mode particles to accumulation mode particles. Thus, the number of particles have decreased while the diameter have increased. 
DMDF mainly diffusive mode PSD analysis is summarized for $75 \%$ and $100 \%$ engine loads in figure 13. Comparing DMDF results with CDC mode, results suggest a similar behavior due to the diffusive nature of the combustion. Thus, both combustion strategies are dominated by large sized particles. The cutoff diameter is $30 \mathrm{~nm}$, due to the peaks observed at the PSD curves. DMDF PSD curves present a peak at $70 \mathrm{~nm}$ at $75 \%$ engine load, and a peak of $90 \mathrm{~nm}$ at $100 \%$. In addition, both strategies are suitable to use the same cutoff diameter because of the PSD peak at $70 \mathrm{~nm}$ observed for CDC.

Nucleation mode particles represent a small fraction from the total quantity of particles at CDC mode. However, the difference between accumulation mode and nucleation mode at DMDF mainly diffusive is considerably due to the order of magnitude observed, surely related with the smoke emissions measured. At CDC, the smoke emissions is below 0.2 FSN, whereas at DMDF mainly diffusive the smoke emissions are around 0.81 FSN. Hence, the differences observed in figure 18 justify the number of particles from nucleation and accumulation mode and the relation with the smoke measurements.

\section{Conclusions}

In the present study, PSD study was performed to measure particulate size distribution between diameters from 5-250 nm from CDC and DMDF modes in a compression ignition engine. The PSD curves represented for both operation modes showed different traces. The curves corresponding to the DMDF concept are characterized by having higher number of particles than CDC and the differences found between nucleation and accumulation mode particles is also higher than at CDC mode.

The most relevant conclusions are:

- At CDC FSN measurement presents a direct relationship with the number of particles, but this relation is not always satisfied under DMDF mode.

- The accumulation mode particles have a direct impact on the FSN values, but FSN is not sensitive to nucleation mode particles.

- DMDF concept produces higher quantity of particles while the values of FSN remain around 0 .

- Higher number of particles has been obtained for the DMDF concept at every engine load tested than CDC.

- At DMDF strategy, nucleation mode domination has been moving to accumulation mode domination as the load was increased.

In future works the study will be extended to increase the range of the particle size measurements to 5-1000 nm in order to check the capabilities of DMDF to meet the particle matter emissions limits imposed by the EURO VI regulation.

\section{Acknowledgments}

This investigation has been funded by VOLVO Group Trucks Technology. The authors also acknowledge the Spanish economy and competitiveness ministry for partially supporting this research (HiReCo TRA2014-58870-R). The predoctoral contract of the author V. Boronat (FPI-S2-2017-2882) is granted by the Programa de Apoyo para la Investigación y Desarrollo (PAID) of the Universitat Politècnica de València. The author J. Monsalve-Serrano acknowledges the financial support from the Universitat 
Politècnica de València under the grant "Ayudas Para la Contratación de Doctores para el Acceso al Sistema Español de Ciencia, Tecnología e Innovación".

\section{References}

[1] Luján J.M., Climent H., Dolz V., Moratal A., Borges-Alejo J., Soukeur Z. Potential of exhaust heat recovery for intake charge heating in a diesel engine transient operation at cold conditions. Applied Thermal Engineering, Volume 105, 2016, Pages 501-508.

[2] Payri F., Olmeda P., Martín J., Carreño R. Experimental analysis of the global energy balance in a DI diesel engine. Applied Thermal Engineering, Volume 89, 2015, Pages 545-557.

[3] Payri R., Gimeno J., Bracho G., Vaquerizo D. Study of liquid and vapor phase behavior on Diesel sprays for heavy duty engine nozzles. Applied Thermal Engineering, Volume 107, 2016, Pages 365-378.

[4] Maghbouli A., Lucchini T., D'Errico G., Onorati A. Effects of grid alignment on modeling the spray and mixing process in direct injection diesel engines under nonreacting operating conditions. Applied Thermal Engineering, Volume 91, 2015, Pages 901-912.

[5] Lee Y., Huh K. Analysis of different modes of low temperature combustion by ultrahigh EGR and modulated kinetics in a heavy duty diesel engine. Applied Thermal Engineering, Volume 70, Issue 1, 2014, Pages 776-787.

[6] Qian Y., Zhou Q., Wang X., Zhu L., Lu X. Enabling dual fuel sequential combustion using port fuel injection of high reactivity fuel combined with direct injection of low reactivity fuels. Applied Thermal Engineering, Volume 103, 2016, Pages 399-410.

[7] Garcia A., Monsalve-Serrano J., Heuser B., Jakob M., Kremer F., Pischinger S. Influence of fuel properties on fundamental spray characteristics and soot emissions using different tailor-made fuels from biomass. Energy Conversion and Management, Volume 108, 2016, Pages 243-254.

[8] Çınar C., Uyumaz A., Polat S., Yılmaz E., Can Ö., Solmaz H. Combustion and performance characteristics of an $\mathrm{HCCl}$ engine utilizing trapped residual gas via reduced valve lift. Applied Thermal Engineering, Volume 100, 2016, Pages 586-594.

[9] Cerit M., Soyhan H.S. Thermal analysis of a combustion chamber surrounded by deposits in an $\mathrm{HCCl}$ engine. Applied Thermal Engineering, Volume 50, Issue 1, 2013, Pages 81-88.

[10] Bessonette P., Schleyer C., Duffy K., Hardy W. y Liechty M. Effects of Fuel Property Changes on Heavy-Duty HCCl Combustion. SAE Technical Paper 2007-01-0191, 2007.

[11] Zhang X., Wang H., Zheng Z., Reitz R., Yao M. Experimental investigations of gasoline partially premixed combustion with an exhaust rebreathing valve strategy at low loads. Applied Thermal Engineering, Volume 103, 2016, Pages 832-841.

[12] Benajes J., García A., Domenech V., Durrett R. An investigation of partially premixed compression ignition combustion using gasoline and spark assistance. Applied Thermal Engineering, Volume 52, Issue 2, 2013, Pages 468-477.

[13] Benajes J., Molina S., García A., Monsalve-Serrano J., Durrett R. Conceptual model description of the double injection strategy applied to the gasoline partially premixed compression ignition combustion concept with spark assistance. Applied Energy, Volume 129, 2014, Pages 1-9. 
[14] Benajes J., Molina S., García A., Monsalve-Serrano J., Durrett R. Performance and engine-out emissions evaluation of the double injection strategy applied to the gasoline partially premixed compression ignition spark assisted combustion concept. Applied Energy, Volume 134, 2014, Pages 90-101.

[15] Inagaki K., Fuyuto T., Nishikawa K., Nakakita K., Sakata I. Dual-fuel PCI combustion controlled by in-cylinder stratification of ignitability. SAE technical paper 2006-01-0028, 2006.

[16] Kokjohn S. L., Hanson R. M., Splitter D. A., Reitz R. D. Fuel Reactivity Controlled Compression Ignition (RCCl): A Pathway to Controlled High-Efficiency Clean Combustion. Int. J. Engine Res. Volume 12, 2011, Pages 209-226.

[17] Benajes J, García A, Monsalve-Serrano J, Balloul I, Pradel G. Evaluating the reactivity controlled compression ignition operating range limits in a highcompression ratio medium-duty diesel engine fueled with biodiesel and ethanol. International Journal of Engine Research, Volume 18 (1-2), Pages 66-80, 2017.

[18] Desantes J. M., Benajes J., García A., Monsalve-Serrano J. The role of the incylinder gas temperature and oxygen concentration over low load reactivity controlled compression ignition combustion efficiency. Energy, Volume 78, 2014, Pages 854-868.

[19] Benajes J., Molina S., García A., Monsalve-Serrano J. Effects of low reactivity fuel characteristics and blending ratio on low load $\mathrm{RCCl}$ (reactivity controlled compression ignition) performance and emissions in a heavy-duty diesel engine. Energy, Volume 90, 2015, Pages 1261-1271.

[20] Benajes J., Molina S., García A., Monsalve-Serrano J. Effects of Direct injection timing and Blending Ratio on RCCl combustion with different Low Reactivity Fuels. Energy Conversion and Management, Volume 99, 2015, Pages 193-209.

[21] Benajes J., Pastor J. V., García A., Boronat V. A RCCl operational limits assessment in a medium duty compression ignition engine using an adapted compression ratio, Energy Conversion and Management, Volume 126, 2016, Pages 497-508.

[22] Kakaee A-H., Nasiri-Toosi A., Partovi B., Paykani A. Effects of piston bowl geometry on combustion and emissions characteristics of a natural gas/diesel RCCl engine. Applied Thermal Engineering, Volume 102, 2016, Pages 1462-1472.

[23] Benajes J., Pastor José V., García A., Monsalve-Serrano J. An experimental investigation on the Influence of piston bowl geometry on $\mathrm{RCCl}$ performance and emissions in a heavy-duty engine. Energy Conversion and Management, Volume 103, 2015, Pages 1019-1030.

[24] Benajes J., García A., Pastor J.M., Monsalve-Serrano J. Effects of piston bowl geometry on Reactivity Controlled Compression Ignition heat transfer and combustion losses at different engine loads. Energy, Volume 98, 2016, Pages 64-77.

[25] Benajes J., García A., Monsalve-Serrano J., Balloul I., Pradel G. An assessment of the dual-mode reactivity controlled compression ignition/conventional diesel combustion capabilities in a EURO VI medium-duty diesel engine fueled with an intermediate ethanol-gasoline blend and biodiesel. Energy Conversion and Management, Volume 123, 2016, Pages 381-391.

[26] Benajes J., Pastor J.V., García A., Monsalve-Serrano J. The potential of RCCI concept to meet EURO VI NOx limitation and ultra-low soot emissions in a heavyduty engine over the whole engine map. Fuel, Volume 159, 2015, Pages 952-961. 
[27] Benajes J., García A., Monsalve-Serrano J. and Boronat V. Achieving clean and efficient engine operation up to full load by combining optimized $\mathrm{RCCl}$ and dual-fuel diesel-gasoline combustion strategies. Energy Conversion and Management, Volume 136, 2017, Pages 142-151.

[28] Kittelson D. Engine and Nanoparticles: a Review. Journal of Aerosol Science, Vol. 29, 1998, Pages 575-588.

[29] Shi J., Harrison R., Brear F. Particle size distribution from a modern heavy duty diesel engine. The Science of the Total Environment, 235, 1999, Pages 305-317.

[30] Armas O., Gómez A., Mata C., Ramos A. Particles emitted during the stops of an urban bus fuelled with ethanol-biodiesel-diesel blends. Urban Climate, Volume 2, 2012, Pages 43-54.

[31] Armas O., Gómez A., Mata C., Ramos A. Particle size distributions from a city bus fuelled with ethanol-biodiesel-diesel fuel blends. Fuel, Volume 111, 2013, Pages 393-400.

[32] Storey J., Curran S., Lewis S., Barone T., Dempsey T, Moses-DeBusk M., Hanson M., Prikhodko V., Northrop W. Evolution and current understanding of physicochemical characterization of particulate matter from reactivity controlled compression ignition combustion on a multi cylinder light-duty engine. International Journal of Engine Research, 2016.

[33] Prikhodko V., Curran S., Barone T., Lewis S. et al. Emission Characteristics of a Diesel Engine Operating with In-Cylinder Gasoline and Diesel Fuel Blending. SAE Int. J. Fuels Lubr., 2010, Pages 946-955.

[34] Lucachick, Glenn, Scott Curran, John Storey, Vitaly Prikhodko, and William F. Northrop. 2016. "Volatility Characterization of Nanoparticles from Single and DualFuel Low Temperature Combustion in Compression Ignition Engines." Aerosol Science and Technology 50 (5): 436-47.

[35] Northrop, William F., Praveen V. Madathil, Stanislav V. Bohac, and Dennis N. Assanis. 2011. "Condensational Growth of Particulate Matter from Partially Premixed Low Temperature Combustion of Biodiesel in a Compression Ignition Engine." Aerosol Science and Technology 45 (1): 26-36

[36] Kolodziej C., Wissink M., Splitter D., Hanson R. et al. Particle Size and Number Emissions from RCCl with Direct Injections of Two Fuels. SAE Technical Paper, 2013.

[37] Zhang Y., Ghandhi J., and Rothamer D. Comparison of Particulate Size Distributions from Advanced and Conventional Combustion - Part I: $\mathrm{CDC}, \mathrm{HCCl}$, and RCCI. SAE Int. J. Engines, 2014.

[38] Northrop W, Bohac S, Chin J and Assanis D. Comparison of filter smoke number and elemental carbon mass from partially premixed low temperature combustion in a direct-injection diesel engine. Journal of Engineering for Gas Turbines and Power 2011; 133: 102804.

[39] Curran S., Prikhodko V., Cho K., Sluder S., Parks J., Wagner R., et al. In-cylinder fuel blending of gasoline/diesel for improved efficiency and lowest possible emissions on a multi-cylinder light-duty diesel engine. SAE technical paper 2010-012206, 2010.

[40] Benajes J., García A., Monsalve-Serrano J., Boronat V. Dual-Fuel Combustion for Future Clean and Efficient Compression Ignition Engines. Applied Sciences 7(1):36, 2017. 
[41] Kittelson DB. Engines and nanoparticles: a review. Journal of Aerosol Science 1998; 29(5/6):575-88.

[42] Harris Stephen J., Maricq M.Matti. Signature size distributions for diesel and gasoline engine exhaust particulate matter. Journal of Aerosol Science, 2001; 32: 749-764, ISSN 0021-8502.

[43] Wang B., Mosbach S., Schmutzhard S., Shuai S., Huang Y., Kraft M. Modelling soot formation from wall films in a gasoline direct injection engine using a detailed population balance model. Applied Energy, Volume 163, 2016, Pages 154-166.

\section{Abbreviations}

AIM: Aerosol Instrument Manager

aTDC: After Top Dead Center

CAD: Crank Angle Degree

CA10: Crank angle at $10 \%$ mass fraction burned

CA50: Crank angle at 50\% mass fraction burned

CA90: Crank angle at $90 \%$ mass fraction burned

CDC: Conventional Diesel Combustion

$\mathrm{Cl}$ : Compression Ignition

CO: Carbon Monoxide

CPC: Condensation Particle Counter

CR: Compression Ratio

DI: Direct Injection

DMA: Differential Mobility Analyzer

DMDF: Dual Mode Dual Fuel

ECU: Engine Control Unit

EGR: Exhaust Gas Recirculation

EOI: End of Injection

EU: European Union

EVO: Exhaust Valve Open

GF: Gasoline Fraction

FSN: Filter Smoke Number

uHC: Unburned Hydro Carbons

$\mathrm{HCCl}$ : Homogeneous Charge Compression Ignition

IMEP: Indicated Mean Effective Pressure 
IVC: Intake Valve Close

IVO: Intake Valve Open

LHV: Lower Heating Value

LTC: Low Temperature Combustion

MON: Motor Octane Number

OEM: Original Equipment Manufacturer

ON: Octane Number

PCCl: Partially Charged Compression Ignition

PFI: Port Fuel Injection

PPC: Partially Premixed Charge

PRR: Pressure Rise Rate

PSD: Particle Size Distribution

RCCl: Reactivity Controlled Compression Ignition

RoHR: Rate of Heat Release

RON: Research Octane Number

SCE: Single Cylinder Engine

SMPS: Scanning Mobility Particle Sizer

SOC: Start of Combustion

SOI: Start of Injection

TDC: Top Dead Center 